\title{
Urban Regeneration by Law. Towards the Definition of an Uncertain Term
}

\author{
Valerio Cutini ${ }^{1, a}$, Simone Rusci $i^{1, a}$ \\ ${ }^{1}$ University of Pisa, Department of Energy, Systems, Territory, and Construction Engineering, Largo \\ Lucio Lazzarino - Pisa, Italy \\ ${ }^{1}$ valerio.cutini@ing.unipi.it, ${ }^{2}$ simone.rusci@ing.unipi.it
}

Keywords: Urban Regeneration, Land Use, Sustainability.

\begin{abstract}
On September 30, 2013, the Giunta Regionale Toscana has approved a bill that is presumably destined to substitute the current regional law on the Governo del Territorio (L.R. 01/2005). The new law is going to prevent the new soil occupation for housing, thus radically and definitely closing the long lasting historic phase of the urban growth planning, hegemonic for over 80 years. The renovation and reuse of interstitial areas and the urban regeneration are therefore going to become the only possible intervention for supplying the housing needs of cities and local communities. The proposal has excited a strong debate among opposite sides of politicians, administrations, economic operators, professional and town planners; the law and the debate it is exciting is likely to strongly influence both the legislation of other Italian regions and, at a national scale, the bills on territorial and environmental issues to be discussed by the Italian Parliament commissions.

The transition of urban regeneration from the project sphere, often limited within local and punctiform operations, towards a process-oriented and diffused approach involves the urgent needs to pinpoint new shared tools, suitable for managing and controlling complex and codified procedures, multiplicity of involved subjects and the transparent participation of local communities. The definition of such tool as planning support is certainly essential for the political intentions and law regulations to concretely determine new operational method.

The purpose of this paper is to briefly sketch the state of the art of the present methods and procedures at urban and territorial scale as well as to outline new approaches and developments so as to meet the new normative needs concerning the regeneration.
\end{abstract}

\section{Introduction}

The debate on town planning issues and the laws and regulations have always nourished a dialectic relationship that can be acknowledged as fundamental for the development of the government of territorial plans and projects: in general, as it appears obvious, due to the influence of the former on the latter ones, which receive and gather indications, addresses and orientations provided by the scientific debate and publications and translate them into laws and prescriptions, so as to dictate the rules for any operation. In Italy, in particular, the great law innovations in town planning (zoning regulation, territorial standard, land tenure, complex plans, etc.) have all along been the concrete, and often long expected, outcome of scientific engagement and cultural struggle.

Nonetheless, such relationship has often arisen in the opposite sense, being the laws and regulations, sometimes even embryonically conceived, aimed at arousing and requesting the definition of questions and operational praxis.

Something like that actually occurred in the first ' $90 \mathrm{~s}$ with the transition from the sphere of renovation to the notion of requalification: the legislation (Italian law 179/92 and D.M. 08/10/1998 in particular), gathering the outcome of the debate on the problems with planning on brownfield areas, had pushed for the definition of the operational procedures of PRIU (Piano di Riqualificazione Urbana) and PRUSST (Piano di Riqualificazione Urbana e di Sviluppo Sostenibile del Territorio). And it can't be denied that the results (often deluding) of several urban plans and projects worked out in the last ' 90 s are to a certain extent to be ascribed to the lacking of a shared conceptual framework. 
In these last few months, something similar appears to happen on the wide issue of urban regeneration, variously faced by Italian regional laws. On the one hand, those laws are clearly the political answer to the wide debate around the theme of soil consumption and of the need of limitation of urban sprawl. On the other side, it ought to be noticed that those laws themselves do actually introduce aspects and themes still open and not yet defined, thus pushing for a concrete contribution from the scientific debate and disciplinary exchange.

The bill approved on Sept. $30^{\text {th }}, 2013$ by the Giunta Regionale Toscana and intended at taking place of the current regional law on the Governo del Territorio (Legge Toscana 1/2005), which is aimed at preventing new land occupation for urban growth, actually presents an epochal significance, in that it is going to close out the historic parabola of urban growth planning, hegemonic in the last 80 years, and to focus on the urban regeneration for the renovation and reuse of already urbanized areas, which will actually remains the only possible operation for meeting any housing need [1].

If, then, the Tuscan bill closes (somehow emphatically) a long lasting historic page, as a matter of fact (and much more subtly) it opens a new phase, which appears uncertain so as to be presented and subjected to the scientific and disciplinary debate: what in concrete terms the notion of urban regenerations stands for, how the areas to be regenerated are to be recognized and identified, how the development process is to be actually managed, actively involving stakeholders and local communities.

\section{The theme of regeneration}

In the last few years, the notion of urban regeneration has gone presenting a fast diffusion, arousing the common, keen interest of both technicians and administrations. Yet, such a fast diffusion has not corresponded to the definition of a univocal and shared meaning of the term, which on the contrary at present is actually used in a polysemous manner, with meanings often far different one from another. It's therefore necessary to try to precise and codify the notion of regeneration, distinguishing the term 'rigenerazione urbana' with respect to other similar terms, more used and consolidated in Italian common language: not certainly for a mere language clarification, but rather to define and perimeter the working range and to facilitate comparing different operations and experiences.

It's worth specifying that this is a peculiar Italian matter, in that it regards the meaning of Italian terms, which of course won't be translated in the present paper; nonetheless, such matter present strong similarities in other European countries, so as to appear a global question, the question of urban regeneration.

In order to operate a fundamental, rough distinction, it's useful to first define and distinguish those widely used terms that are commonly associated with the notion of regeneration: in particular that is the 'ristrutturazione urbanistica', the 'recupero urbano' and the 'riqualificazione urbana'.

The 'ristrutturazione urbanistica' is the oldest one, as the first to be introduced into the Italian normative language: The L. 1150/1942 and more recently the DPR 380/2001 identify the 'ristrutturazione urbanistica' as "aimed at substitute the existing urban and building context with a different one, by means of a systematic complex of operations, including also the change in the shape of lots, blocks and urban grid".

The term 'recupero urbano', on the contrary, is used both according to a normative meaning, to define the so-called PRU (Piani di Recupero Urbano) introduced by the law 04.12.1993 n. 493, and an operational meaning, to select and perimeter punctiform operations of urban transformation, such as those aimed at reusing brownfield lands [2].

The notion of 'riqualificazione urbanistica' is more general, and is usually referred to the urban project, frequently used to describe urban transformation operations, detailed up to an architectural scale and detail.

The few lines above let hence to discuss on the existence of element that concretely distinguish the regeneration from those mentioned categories; or if, on the contrary, it ought to be assumed as a 
mere neologism, a trendy synonymous, purely aimed at arousing the attention and the debate on the theme of the reuse of the existing housing stock.

Despite the above definitions, the Italian notions of 'ristrutturazione urbanistica', 'recupero urbano' and 'riqualificazione urbana' actually present several intersections and common aspects, as well as some potential misunderstandings. All the three notions share the following aspects:

- A punctiform location of the urban operations: they operate on delimited and well defined contexts, no matter their dimension: industrial areas, public compounds, railway stations, etc. [3].

- A limited number of involved stakeholders: they are mostly public or public/private partnerships, but anyhow characterized by the presence of a little number of private subjects (companies, industrial firms, businessmen, etc.) and by a unique public subject.

- A strict control by the decision maker subject: the transformation presents two successive phases (planning and operation), within a rigid and pyramidal scheme composed by rules and regulations, just like the traditional town plans.

The use of the new notion of regeneration can hence be determined and justified only by a relevant difference in the proposed methodology with respect to the existing one; even more, the different approach should be aimed at overcoming the problems and the difficulties so far arisen.

The new urban policies, and the regeneration among them, are requested to provide pursuing public goals and maintaining urban and social welfare within a context that is characterize by an unprecedented scarcity of resources, both public and private. An additional cultural and normative restriction is that such operation must respect and protect the natural resources, so as to be assumed as sustainable. It's then not casual that the issue of urban regeneration is mostly linked (as in the case of the Tuscan regional law) to the matter of land consumption, and has strongly arisen just in these years of economic crisis, with the cut off of public financial intervention: what makes regeneration suitable for link together and synthesize environmental issues and economic and financial aspects.

As deriving from Latin genus (birth, formation), the etymology of the term suggests that in the regeneration the traditional binomial presence planning-operation is to be substituted by the new induction-management one. Urban regeneration is in fact induced, given the actual necessity and potentiality of the operation, by means of planning and evaluation tools, aimed at stimulate spontaneous and self-sustained transformations. In such approach, the urban plans only provide general development criteria, and their spatial design is only limited within the public and collective sphere, to be faced using the plus values generated by the private intervention.

In such view, the urban regeneration not only operates onto the vacant and brownfield lands (what would make it to coincide with the 'recupero urbano'), but also on the consolidated urban context, either public and private, as well as still functionally working. The resources, as sketched above, are to be mostly pinpointed within the private sphere, which concurs in improving and redefining the public city by means of the increase of their real estate values.

The regeneration does hence operate diffusely [3], both at a micro-scale (for instance the energetic requalification of buildings or the construction of cable data network) and at a macroscale, aimed at the transformation/substitution of whole urban compounds.

The range of the involved subjects is extended and highly diversified, characterized by the copresence of the traditional economic operators (firms, real estate companies, etc.) and single private subjects, interacting towards common and compatible targets.

What mainly differentiates the urban regeneration with respect to the used or traditional way of intervention on the existing building stock is therefore its process oriented intrinsic nature, aimed at activating various phenomena of urban transformation by means of the involvement of different subjects: in other words, much more an urban policy rather than a mere project, so as to involve town planning, fiscal, social, economic and cultural measures.

Summing all up, the regeneration (Fig.1) can hence be briefly said characterized by:

- diffusion and multiscalarity of the intervention; 
- involvement of numerous and heterogeneous subjects;

- mainly private financial funding;

- planning as a process rather than a project.
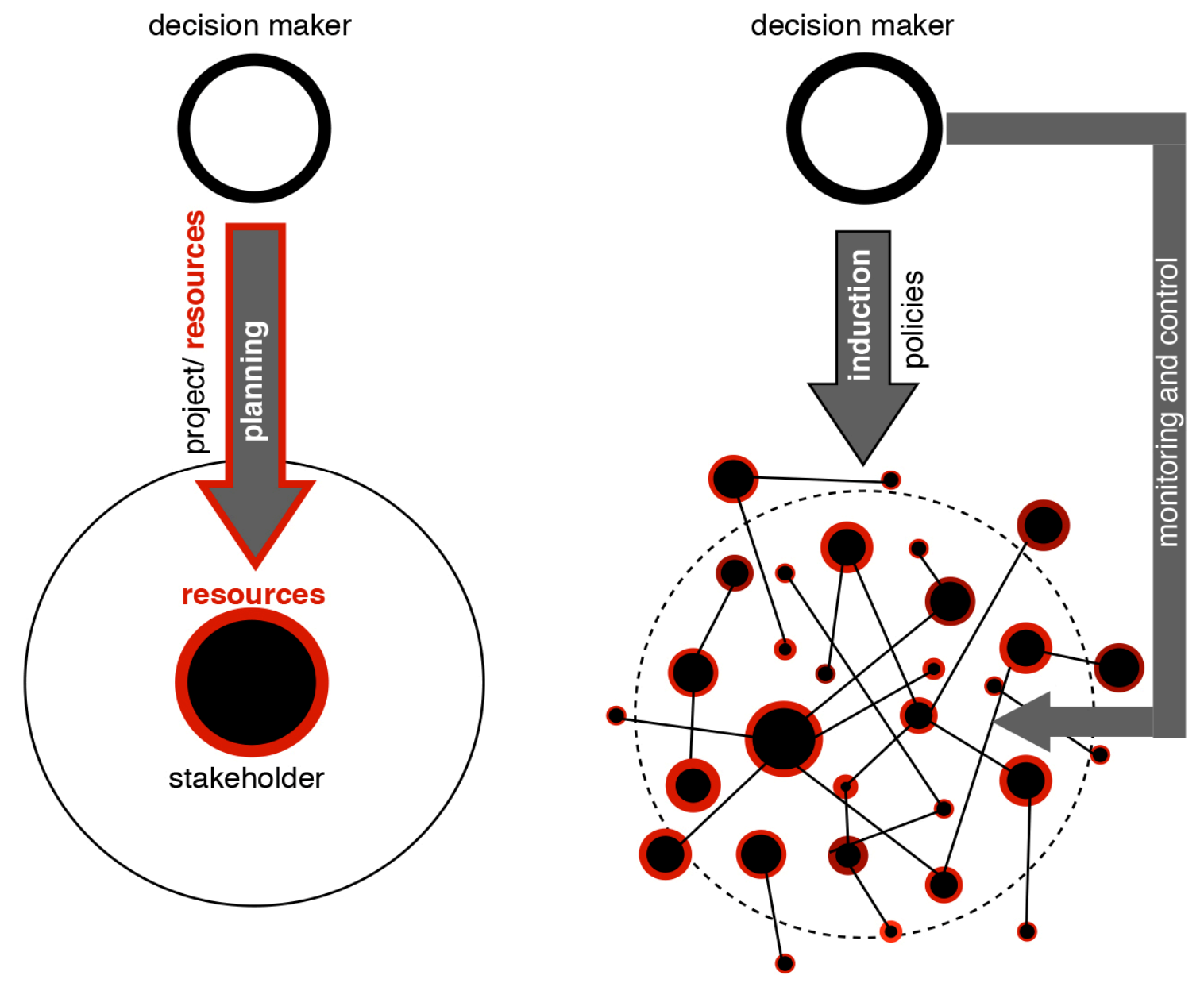

Fig.1. Urban renovation vs. regeneration - a comparison

\section{Towards a shared methodology}

The recent Tuscan bill first introduces into a regional legislation (in Italy since 2001 town and territorial planning are exclusive competence of regions) operational prescriptions aimed at limiting land consumption, asserting that infrastructural and housing needs ought to be uniquely fulfilled by the renovation and reuse of already urbanized areas, and not using agricultural lands.

The new law, unlike the preceding ones that yet included similar regulations, does actually specify the general criteria for distinguishing urban and rural areas, so as to guarantee their actual implementation.

Although the term 'rigenerazione urbana' is not explicitly mentioned, still it appears clearly intended at becoming, along with punctiform renovation operations, the main tool for the redefinition of Tuscan territory and cities.

This new regulation therefore marks out the long awaited matching between the issues of urban regeneration and land use [4], often wrongly considered distinct themes. An incisive regeneration policy, as a matter of fact, appears hardly compatible with the traditional growth planning, both for the higher operational costs and for the 'political' concurrency in decision making process coming from land rent owners [5]. The development of urban regeneration from a mere academic context to 
a normative and operational sphere does hence appear a crucial starting point towards the working out of new territorial plans, suitable for managing such innovations.

Traditional Italian territorial plans, although having gained in the last twenty years a strategic dimension, nonetheless appear oriented towards the physical territorial and urban transformation, still conserving (much more than in other European countries) prominent project features. In light of the definition of urban regeneration, they therefore appear unsuitable for managing medium and long-term processes, characterized by high complexity and by many heterogeneous stakeholders, in the bargain not spatially determined.

If we consider the present articulate Italian administration and bureaucracy, so frequently criticized, it hence appears risky to introduce a further kind of sector plan - something like a regeneration plan' -, which would inevitably represent a further burden for the complicated planning procedure, so as to become the nth purely formal fulfilment, lacking in real effects on the actual planning process.

Aiming then at finding. among those already existent, a kind of territorial tool suitable for being integrated so as to take into account the regeneration policies, we cannot but acknowledge the VAS (Valutazione Ambientale Strategica, Italian for Strategic Environmental Assessment) as the most adapt and at present available. On such regard, three aspects, narrowly connected to the issue of regeneration, are worth mentioning:

- the multidisciplinary and multiscalar approach; by definition, the Strategic Environmental Assessment itself is a discussion, exchange and synthesis tool among different disciplinary spheres and various problems scales [6];

- the links with evaluation tools; the complexity of regeneration and the need of determining spatially non-defined policies ask for tools (such as the Strategic Environmental Assessment) suitable for analyzing and objectively comparing several alternative solutions;

- the links with the decision making process; the evaluation, just like the regeneration, goes through three consequential phases (ex-ante, in itinere and ex-post), so as to respectively guarantee the analysis of the territorial context, the definition of the policies and the monitoring of the results.

In such view, the VAS, in Italy in these days object of discussion concerning its actual effectiveness within the making decision and planning process, could play a crucial role in territorial planning, both as a preparatory and integrated tool, suitable for managing the transformation processes according to the logic of sustainability and participation.

\section{Conclusions}

The recent normative innovations, both national and regional (regional laws of Lombardy and Tuscany), together with present economic circumstance and real estate market trends, appear destined at radically and rapidly modify the framework of Italian town planning policies.

The increasing diffusion and accuracy of studies on land use and consumption as well as the environmental impacts of urban growth have gone favouring a common awareness of the need of incisive and effective territorial policies, rather than generic wishes or intents assertions.

On this regards, at present Tuscany is the first region in line, as it has proceeded reforming its regional law that is going to radically block any use of agricultural lands for housing and infrastructures. For the first time urban regeneration and renovation become the unique modality for meeting housing needs. It's then essential to define and share urban regeneration as an effective operational procedure rather than a mere lexical restyling.

In order to define new possible interventions as well as an actual improvement of housing stock (without public funding, presently unavailable) four features are to characterize the conceptual framework of the notion of regeneration:

- diffusion and multiscalarity of the intervention;

- involvement of numerous and heterogeneous subjects;

- mainly private financial funding; 
- planning as a process rather than a project.

On the other side, operational tools for assuring the real fulfilment of regeneration are urgently required. For this aim, the use of Strategic Environmental Assessment (VAS in Italy), thanks to its systemic nature, appears suitable for determining a double effect: on the one hand, it would prevent introducing new procedures into (thus overloading) the already crowded and complicated Italian town planning process; on the other hand, it would help redefining the actual role of VAS, which in the Italian decision making process Italy is scarcely effective and incisive.

The integration of urban regeneration within EIA procedure would be likely to involve relevant fallouts on territorial planning. Necessarily, the implementation of an objective and measurable parameter (even though radical and somehow rough) for land use will in fact determine a new balance between strategic planning and operational planning, which in Italy is presently characterized by the prevailing of the latter on the first one.

At present, the dimensioning of housing stock, which is a typical prerogative of strategic planning, is uniquely worked out by the prevision of forthcoming housing needs, on the basis of a virtually unlimited areas stock (the rural areas surrounding the settlements), to be implemented by the operational planning procedures.

The availability of unlimited spatial resources is hence what makes dimensioning a highly flexible operation, easily and frequently subject to continuous changes and adjustments.

On the contrary, the a-priori assignation of a limited housing stock - objectively determined and hence unchangeable - will provide strategic planning (and therefore also the EIA) with an incisive role with respect to operational planning, so as to balance the strategic and operational phases.

Summing all up, the nature itself of urban regeneration and land use policies, as they were sketched so far, could be suitable for favouring the passage from a two-phases planning (operational, implementation) towards a circular four-phases planning (strategic, operational, implementation, monitoring). What will hence allow meeting the European principle (ratified by the EU Directive 42/2001/CE) of a complete adherence between decision making and planning process.

\section{References}

[1] S. Rusci: La Riforma della Legge Toscana in materia di Governo del Territorio. Un passo oltre la contrapposizione, in EyesReg vol.3 n. 4, (2013)

[2] C. Agnoletti, R. Innocenti, P. Lattarullo: Densificazione e rigenerazione urbana: Evoluzione delle politiche di riuso delle aree dismesse, Paper, XXXII Conferenza italiana di Scienze Regionali (2011)

[3] P. Vitillo: Dalla riqualificazione alla rigenerazione urbana. Nodi, temi, criticità, in Urbanistica Informazioni, n. 251, INU edizioni (2013)

[4] S. Stanghellini, Complessità del progetto di rigenerazione urbana: funzionamento dell'intervento, in: Urbanistica Informazioni, n. 251, INU edizioni (2013)

[5] L. Nespolo: Rigenerazione urbana e recupero del plusvalore fondiario, IRPET Regione Toscana (2012)

[6] L. Fusco Girard, P. Nijkamp: Le Valutazioni per lo sviluppo sostenibile della città e del territorio, Franco Angeli (2000) 